\title{
Endoscopic hemostasis using a gauze-ball compression method
}

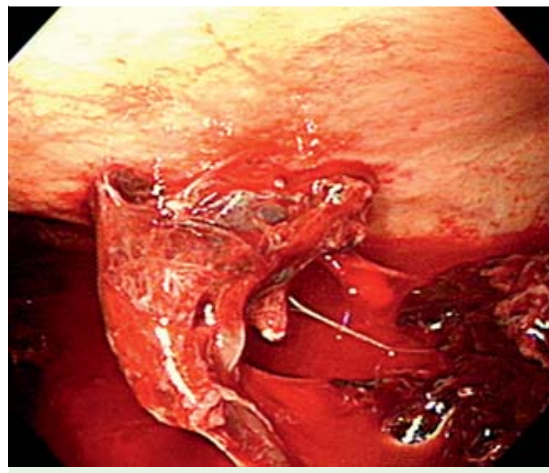

Fig. 1 View during follow-up endoscopy showing active bleeding from the posterior wall of the upper gastric body.

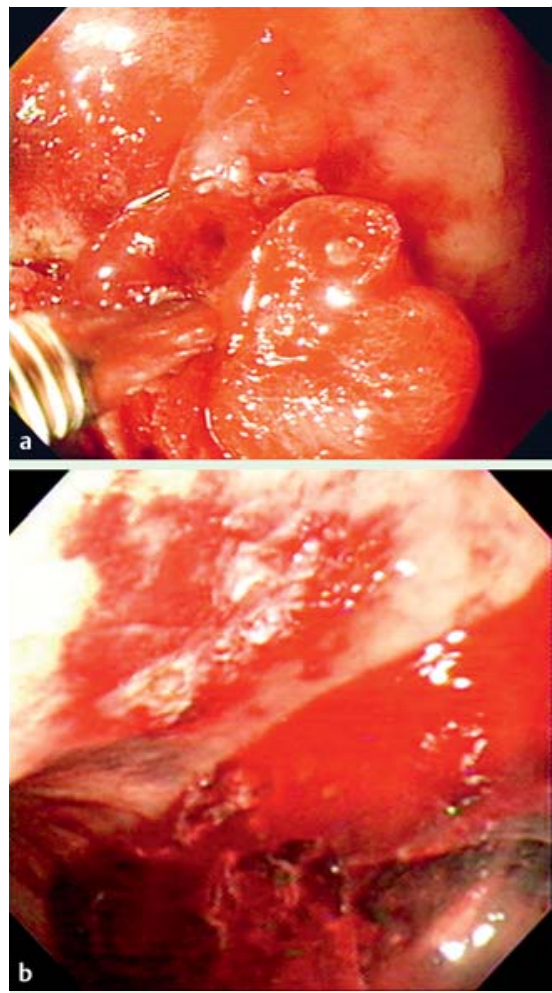

Fig. 3 Endoscopic views showing: a the gauze ball being applied to the bleeding site with compression being maintained for about 3 minutes; $\mathbf{b}$ cessation of the bleeding immediately after compression with the gauze ball.

Direct compression of a bleeding site is the most fundamental hemostatic method. Despite this, endoscopic methods based on this principle have yet to be reported. Herein, we describe our experience with endoscopic hemostasis using a gauze-ball compression method.

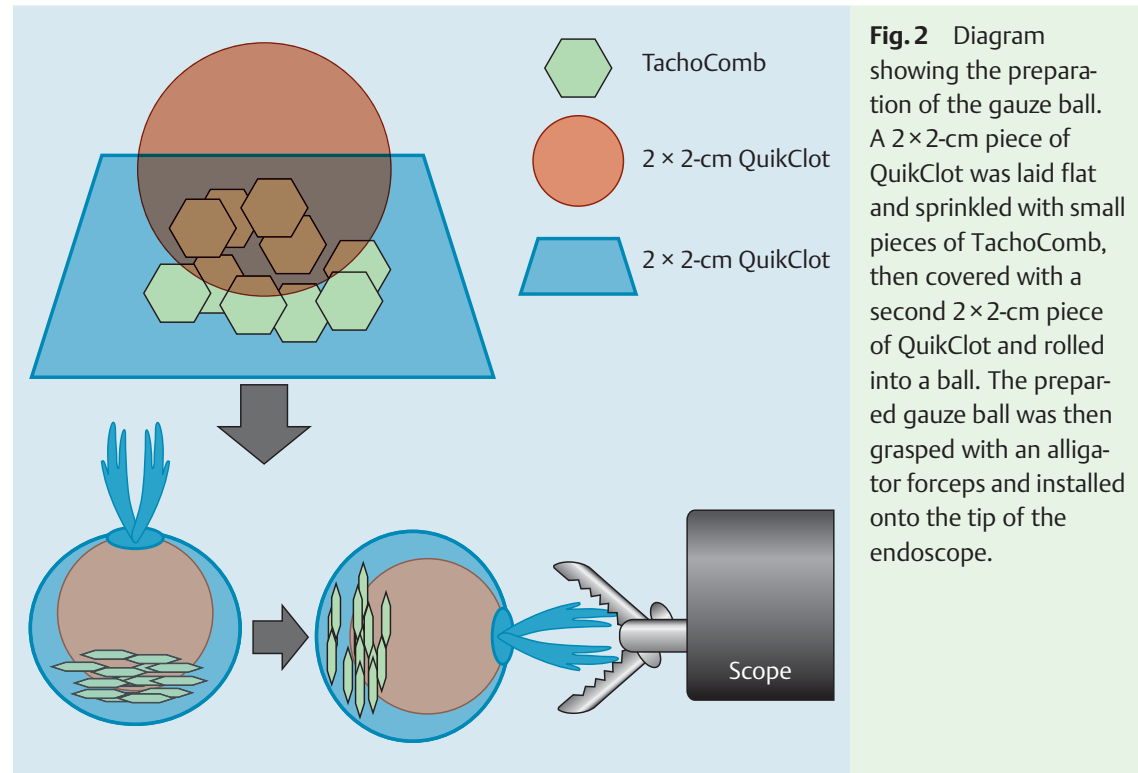

A 76-year-old man was hospitalized for hematemesis. His blood pressure dropped to $72 / 44 \mathrm{mmHg}$, his pulse rate was elevated at 102 beats per minute, and his hemoglobin level decreased to $7.5 \mathrm{~g} / \mathrm{dL}$. Immediate endoscopy showed a gastric ulcer with active bleeding on the posterior wall of the upper body.

To control the ulcer bleeding, an epinephrine solution was first injected, and this was followed by the application of three hemoclips; however, this failed to work because of the friability of the mucosa. Argon plasma coagulation and fibrin glue injection also failed. After these attempts at hemostasis failed, angiography was performed, during which contrast leakage from the branch of the left gastric artery was noted. Embolization also failed, however, because superselection of the bleeding vessel was not possible owing to technical difficulties.

A further endoscopy was performed the next day. Active bleeding was noted at the posterior wall of the upper body ( $\bullet$ Fig. 1). A gauze ball was prepared as shown in the diagram ( $\bullet$ Fig. 2 ), then grasped by alligator forceps and held at the tip of the endoscope. The prepared endoscope was then inserted into the stomach through an overtube and the gauze ball was used to mechanically compress the bleeding site ( Fig. 3a). After 3 minutes of mechanical compression with the gauze ball, the

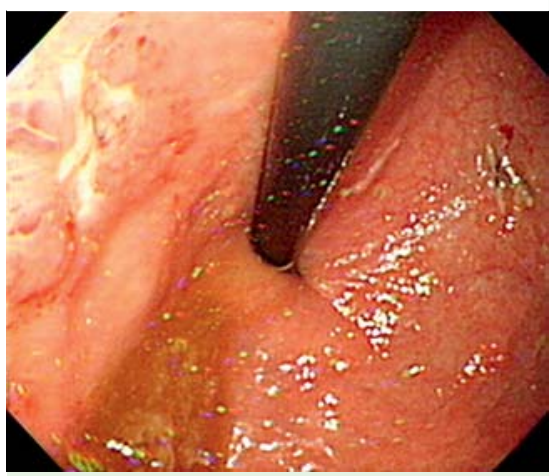

Fig. 4 Follow-up endoscopy showing no further signs of bleeding.

bleeding stopped ( Fig.3b). Follow-up endoscopy 10 days later showed no further signs of bleeding ( $\bullet$ Fig. 4).

In addition to the direct compression on the bleeding site, the hemostatic contribution from two different topical hemostatic agents seemed to work effectively. The main ingredient of QuikClot is kaolin. When kaolin comes into contact with blood, it absorbs the smaller water molecules from the blood. The larger platelets and clotting factors remain in a highly concentrated form, thereby promoting rapid natural clotting [1].

TachoComb, a collagen-bound fibrin sealant, contains human fibrinogen with equine collagen as a carrier. It works by mimicking the final steps of the natural 
blood clotting process, creating a fibrin clot at the bleeding site [2]. This case supports the potential value of a method involving application of gauze-ball compression for endoscopic hemostasis.

Endoscopy_UCTN_Code_TTT_1AO_2AD

Competing interests: None

Seung Hwan Shin ${ }^{1,2}$, Hee Seung Lee ${ }^{1,2}$, Jaehyun Bae ${ }^{1}$, Jun Chul Park1,2, Sung Kwan Shin ${ }^{1,2}$, Sang Kil Lee ${ }^{1,2}$, Yong Chan Lee ${ }^{1,2}$, Hyunsoo Chung ${ }^{1,2}$

${ }^{1}$ Department of Internal Medicine, Yonsei University College of Medicine, Seoul, Korea

${ }^{2}$ Institute of Gastroenterology, Yonsei University College of Medicine, Seoul, Korea

\section{References}

1 Politi L, Aprile A, Paganelli C et al. Randomized clinical trial on short-time compression with Kaolin-filled pad: a new strategy to avoid early bleeding and subacute radial artery occlusion after percutaneous coronary intervention. J Interv Cardiol 2011; 24: $65-72$

2 Rickenbacher A, Breitenstein S, Lesurtel M et al. Efficacy of TachoSil a fibrin-based haemostat in different fields of surgery - a systematic review. Expert Opin Biol Ther 2009; 9: 897-907

\section{Bibliography}

DoI http://dx.doi.org/ 10.1055/s-0034-1377392 Endoscopy 2014; 46: E395-E396

(c) Georg Thieme Verlag KG Stuttgart · New York ISSN 0013-726X

\section{Corresponding author} Hyunsoo Chung, MD

Division of Gastroenterology Department of Internal Medicine Yonsei Institute of Gastroenterology Yonsei University College of Medicine 250 Seongsanno, Seodaemun-gu

Seoul 120-752

Republic of Korea

Fax: +82-2-3936884

HCHUNG@yuhs.ac 